\title{
Potencial de trilhas como prática de Educação Ambiental em Unidade de Conservação dentro de um campus universitário no município de Fortaleza-CE
}

\author{
Potential of trails as a practice of Environmental Education in a Conservation Unit within a
} university campus in the municipality of Fortaleza-CE

\author{
M. A. Almeida-Filho ${ }^{1 *}$; J. C. de Souza ${ }^{2}$; G. S. R. Rodrigues ${ }^{3}$; R. M. de S. \\ Mendes $^{4}$; L. D. M. Pantoja ${ }^{4}$ \\ ${ }^{1}$ Centro de Ciências Biológicas e da Saúde, Universidade Federal Rural do Semi-Árido, 59625-900, Mossoró-Rio \\ Grande do Norte, Brasil
}

${ }^{2}$ Departamento de Química e Meio Ambiente, Instituto Federal de Educação, Ciência e Tecnologia do Ceará, 61939140, Fortaleza-Ceará, Brasil

${ }^{3}$ Departamento de Biologia, Universidade Federal do Ceará, 60355-636, Fortaleza-Ceará, Brasil

${ }^{4}$ Centro de Ciências da Saúde, Universidade Estadual do Ceará, 60714-903, Fortaleza-Ceará, Brasil

*maarkos.ma@gmail.com

(Recebido em 21 de julho de 2020; aceito em 01 de setembro de 2020)

\begin{abstract}
O Sistema Nacional de Unidades de Conservação da Natureza foi instituído para minimizar os impactos ambientais e/ou antrópicos negativos, e proteger ecossistemas e a biodiversidade, sendo uma destas formas, a promoção de trilhas. Com isso, objetivou-se identificar o conhecimento sobre o conceito de Unidades de Conservação e o potencial de trilhas como prática de Educação Ambiental em uma universidade pública, no município de Fortaleza, Ceará. Foram aplicados questionários com 50 graduandos e graduados do curso de Licenciatura em Ciências Biológicas da Universidade Estadual do Ceará, campus Itaperi, entre abril e junho/2019. Predominou participantes do sexo feminino (58\%) e com faixa etária entre 19-21 anos (42\%); $88 \%$ conheciam o significado de Unidade de Conservação, associando principalmente à Área de Proteção Ambiental (72,72\%); $62 \%$ já participaram de trilhas; apenas $28 \%$ conheciam a área verde da universidade; $96 \%$ gostaram dos percursos realizados, afirmando que trilhas atraem público para visitação e a interação com o meio ambiente (90\%) é o principal atrativo; a importância/contribuição de trilhas em Unidade de Conservação mais notável foi para a Educação Ambiental (96\%); para todos as trilhas realizadas possuem potencial como prática de Educação Ambiental e citaram conscientização (98\%) e impactos ambientais (98\%) como temáticas a serem abordadas em ações de Educação Ambiental nas trilhas. A realização de trilhas proporciona, a diferentes públicos, conhecimentos e experiências com a natureza, à medida que a Educação Ambiental ajuda na preservação/conservação ambiental e no turismo sustentável. Dessa forma, o campus possui potencial ecológico para diferentes atividades como Educação Ambiental e ecoturismo. Palavras-chave: áreas verdes, conscientização ambiental, preservação.
\end{abstract}

The National System of Nature Conservation Units was established to minimize negative environmental and/or anthropogenic impacts and to protect ecosystems and biodiversity, one of these ways being the promotion of trails. The objective was to identify knowledge about the concept of Conservation Units and the potential of trails as a practice of Environmental Education in a public university in the city of Fortaleza, Ceará. Questionnaires were applied with 50 undergraduates and graduates of the Degree in Biological Sciences of the State University of Ceará, Itaperi campus, between April and June/2019. It predominated female participants (58\%) and with age between 19-21 years old (42\%); $88 \%$ knew the meaning of Conservation Unit, associating mainly the Area of Environmental Protection (72.72\%); 62\% already participated of trails; only $28 \%$ knew the green area of the university; $96 \%$ liked the courses carried through, affirming that trails attract public for visitation and the interaction with the environment (90\%) is the main attraction; the importance/contribution of trails in a Conservation Unit was more remarkable for Environmental Education (96\%); for all the trails carried out they have potential as a practice of Environmental Education and cited awareness (98\%) and environmental impacts (98\%) as themes to be addressed in Environmental Education actions on the trails. The realization of trails provides different audiences with knowledge and experiences with nature, as Environmental Education helps in 
environmental preservation/conservation and sustainable tourism. Thus, the campus has ecological potential for different activities such as Environmental Education and ecotourism.

Keywords: green areas, environmental awareness, preservation.

\section{INTRODUÇÃO}

$\mathrm{Na}$ intenção de proteger áreas naturais com elevada biodiversidade e suas características especiais da fauna, flora, recursos hídricos e geológicos presentes em diferentes ecossistemas e na busca de usufruir dos recursos naturais de forma sustentável, foi instituído sob a Lei ${ }^{\circ}$ 9.985/2000 o Sistema Nacional de Unidades de Conservação- SNUC. Essa lei vem garantindo amplos avanços na preservação e estabeleceu regulamentações quanto à forma de gestão destes ambientes [1]. A criação de uma Unidade de Conservação - UC pode propiciar modificações e diversificados usos para determinadas regiões que sofrem com impactos negativos decorrentes, principalmente, do crescimento urbano, como turismo ecológico, recreação, contato com a natureza, pesquisa científica e trilhas interpretativas [2].

As trilhas consistem em um importante componente cultural empregado pelas diferentes populações ao longo dos tempos e que eram usadas para variadas necessidades básicas, como comunicação e busca por água e alimentos. Atualmente, novas finalidades foram agregadas às trilhas, que passaram a ser de grande importância para atividades como a recreação, proporcionando ao visitante bem-estar, lazer e conexão com o ambiente natural [3].

Nessa perspectiva, as trilhas podem contribuir na concepção ambiental entre as pessoas que frequentam os locais, sendo um grande contribuinte educativo e modificador, possibilitando indagações ecológicas e reflexões próprias aos visitantes [4]. As trilhas ecológicas, em sua maioria, em áreas preservadas e/ou conservadas, ajudam na facilitação do pensamento crítico, quanto à importância dos recursos naturais [5].

Dessa forma, locais como os campi universitários merecem destaque. A exemplo do campus Itaperi da Universidade Estadual do Ceará - UECE, que apresenta um fragmento de Floresta de Tabuleiro e possui potencial para essas atividades, uma vez que apresenta diferentes fitofisionomias e que serve de refúgio para espécies vegetais e animais silvestres que buscam alimento, moradia e área de reprodução e ainda resistem a frequente diminuição e/ou perda de habitat, por conta da urbanização [6,7]. De fato, a urbanização e o crescimento populacional, têm causado modificações no meio ambiente e uma das medidas apontadas para minimizar essa questão é por meio da Educação Ambiental - EA, que proporciona uma visão crítica quanto a essas transformações na natureza [8].

Diante disso, o Ministério do Meio Ambiente - MMA [9] reconhece as trilhas como instrumentos de grande relevância para a aproximação das pessoas com as UC, locais protegidos e importantes para as cidades, principalmente as com elevadas densidades populacionais. Isso acaba permitindo com que os usufruidores das trilhas, passem a reconhecer a biodiversidade local [10], além de proporcionar uma troca de vivência e aplicação mais eficiente de EA.

Dentro de campi universitários, atividades como trilhas ecológicas permitem trabalhar a EA com diferentes públicos, trazendo temas referentes à biodiversidade local, sua importância em uma área urbana e as ameaças constantes sofridas para a manutenção deste ambiente, reforçando assim, a necessidade de trabalhar a EA e preservar/conservar o ambiente. Logo, este trabalho tem como objetivo geral identificar o conhecimento sobre o conceito de UC e o potencial de trilhas como prática de EA em uma universidade pública no município de Fortaleza-CE.

\section{MATERIAL E MÉTODOS}

Para o desenvolvimento deste estudo, foi utilizado como base a abordagem mista (qualitativa e quantitativa) e a pesquisa do tipo experimental proposta por Gil (2008) [11]. Visto que esse método permite a seleção das variáveis que influenciam o objeto de estudo, sendo possível identificar os resultados que estas variáveis produzem no objeto.

O trabalho foi realizado na Universidade Estadual do Ceará, localizada no campus Itaperi, Fortaleza-CE, abrangendo uma área total de 104 hectares (Figura 1). O público-alvo da pesquisa 
envolveu 50 alunos graduados e graduandos do curso presencial de Licenciatura em Ciências Biológicas do Centro de Ciências da Saúde - CCB/CCS da UECE, do $1^{\circ}$ ao $10^{\circ}$ semestre letivo. $\mathrm{O}$ critério de inclusão no estudo, foram alunos que em algum momento possuíram e/ou possuem contato direto com a área de mata durante sua vivência universitária. Logo, foram convidados para participar do presente estudo, membros e ex-membros da Empresa Júnior de Biologia da UECE, calouros do curso, bolsistas e voluntários de laboratórios e grupos de estudos, que desenvolvem atividades e pesquisas de levantamento de biodiversidade no campus.
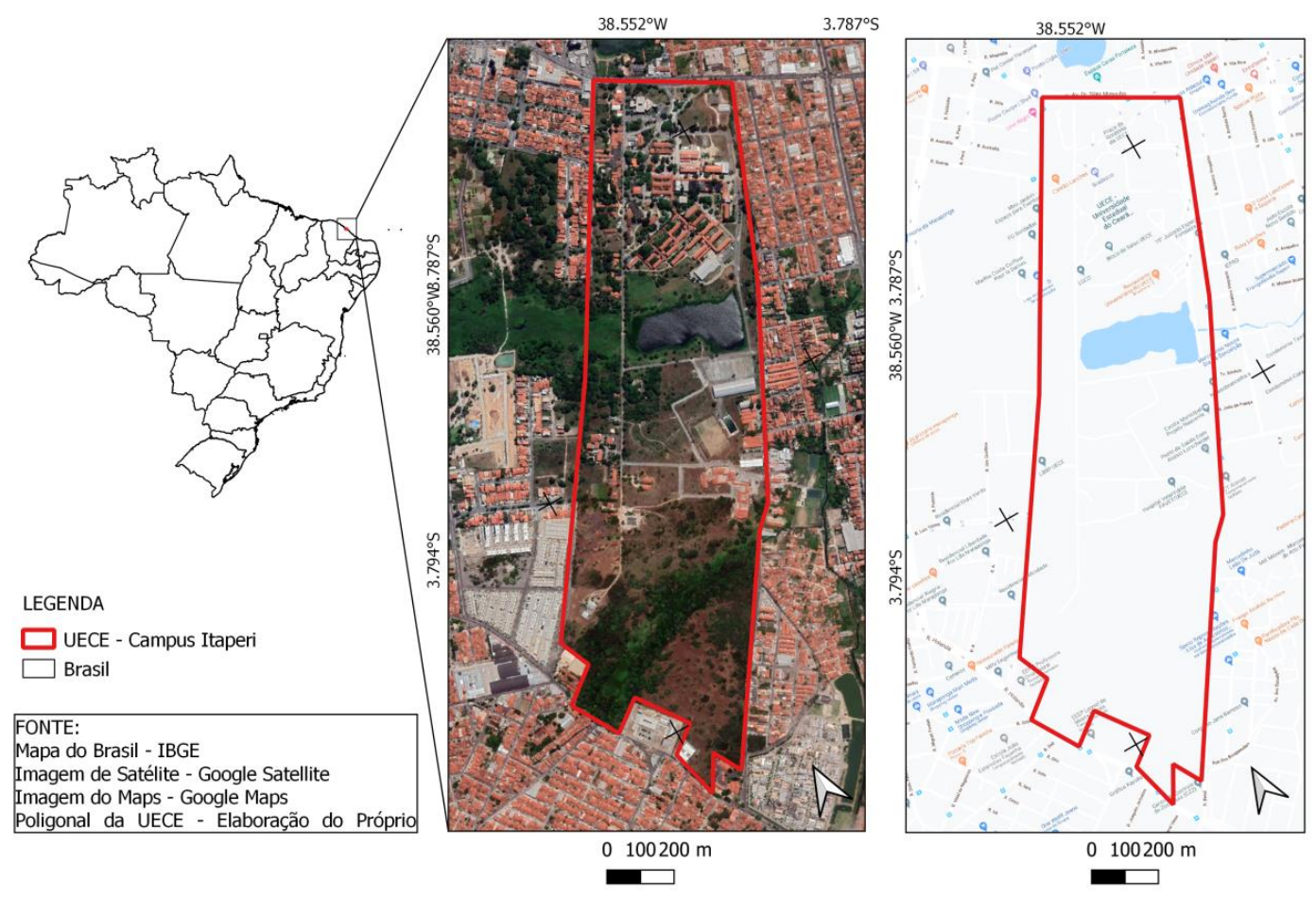

Figura 1: Imagem de satélite com a demarcação da Universidade Estadual do Ceará, campus Itaperi, no município de Fortaleza-CE.

Algumas áreas do campus foram cedidas para estabelecimentos que são de extrema importância para o bairro Serrinha, como: Justiça Especial Cível e Criminal do Tribunal de Justiça do Ceará; Centro de Atenção Psicossocial-Álcool e Drogas; Escola Municipal Projeto Nascente; Centro de Saúde Dom Aloísio Lorscheider; Unidade de Pronto Atendimento; Centro de Controle de Zoonoses; Escola Estadual de Ensino Profissionalizante Leonel de Moura Brizola; Centro de Educação Infantil e Escola de Ensino Fundamental e Médio Professora Diva Cabral [12].

O local de mata em questão está situado na área posterior ao açude, assim como demonstrado na Figura 1 e compreende um fragmento de Floresta de Tabuleiro, com mata secundária de porte arbóreo e arbustivo (Figura 2) [13], caracterizando-se como uma Área de Preservação Permanente - APP que é protegida com base no Novo Código Florestal, instituído pela Lei No .12 .651 de 25 de maio de 2012 [14]. 


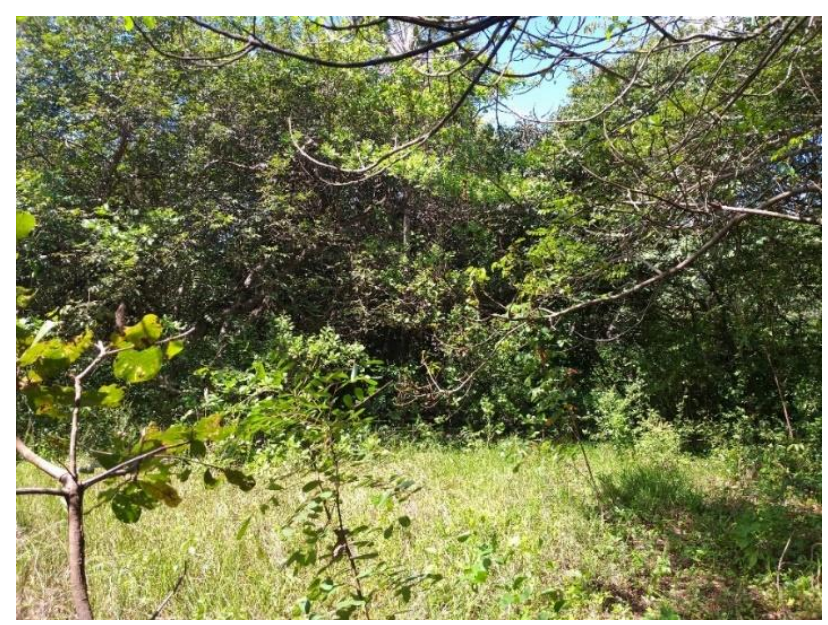

Figura 2: Fragmento de Floresta de Tabuleiro, com mata secundária de porte arbóreo e arbustivo presente na Universidade Estadual do Ceará, campus Itaperi, no município de Fortaleza-CE. Fonte: Almeida-Filho (2019).

\subsection{Aspectos éticos}

A pesquisa respeitou os princípios éticos seguindo a Resolução n ${ }^{\circ}$ 510, de 07 de abril de 2016, do Conselho Nacional de Saúde [15], tais como: autonomia, não maleficência, beneficência e justiça. Foi então, utilizado o Termo de Compromisso Livre e Esclarecido para assegurar os aspectos éticos, garantindo assim o sigilo quanto à privacidade e anonimato dos participantes, $\mathrm{o}$ respeito à dignidade do ser humano sem mutilação ou violação do corpo, riscos e benefícios diretos e também respeitando os valores culturais, sociais, morais, religiosos e éticos [15].

\subsection{Coleta e análise de dados}

A coleta de dados ocorreu no período de abril a junho de 2019, por meio da aplicação de questionários com os 50 participantes. $\mathrm{O}$ questionário foi dividido em quatro partes: (I) caracterização sociodemográfica, com 7 perguntas sobre idade, sexo, situação conjugal, com quem reside, se possuem filhos, se exercem atividade remunerada e semestre; (II) conhecimento sobre UC, com 2 perguntas; (III) vivências e trilha da UECE como potencial, com 6 perguntas com o intuito de obter informações sobre as experiências dos participantes com trilhas externas e no campus e sobre o potencial da trilha da UECE; e (IV) trilha como atividade de EA, com 3 perguntas visando identificar a viabilidade da execução das trilhas com essa finalidade, o que pode ser abordado e em que momentos podem ser aplicadas as trilhas [16, 17, 18].

Os questionários foram aplicados com os participantes presencialmente e através de formulário on-line. Especificamente com os recém-ingressos do curso, a aplicação ocorreu no momento da Semana da Integração do Curso, após a realização da trilha na UECE por intermédio da Empresa Júnior de Biologia, como mostra na sequência de abordagens e registros indicados na Figura 3.

Os dados quantitativos foram analisados por meio do programa Microsoft ${ }^{\circledR}$ Excel 2013, assim como, para a construção dos gráficos. Já os dados qualitativos, foram analisados individualmente e discutidos em cima das temáticas gerais comuns às respostas e através da nuvem de palavras feita a partir do site Word Clouds [19]. 


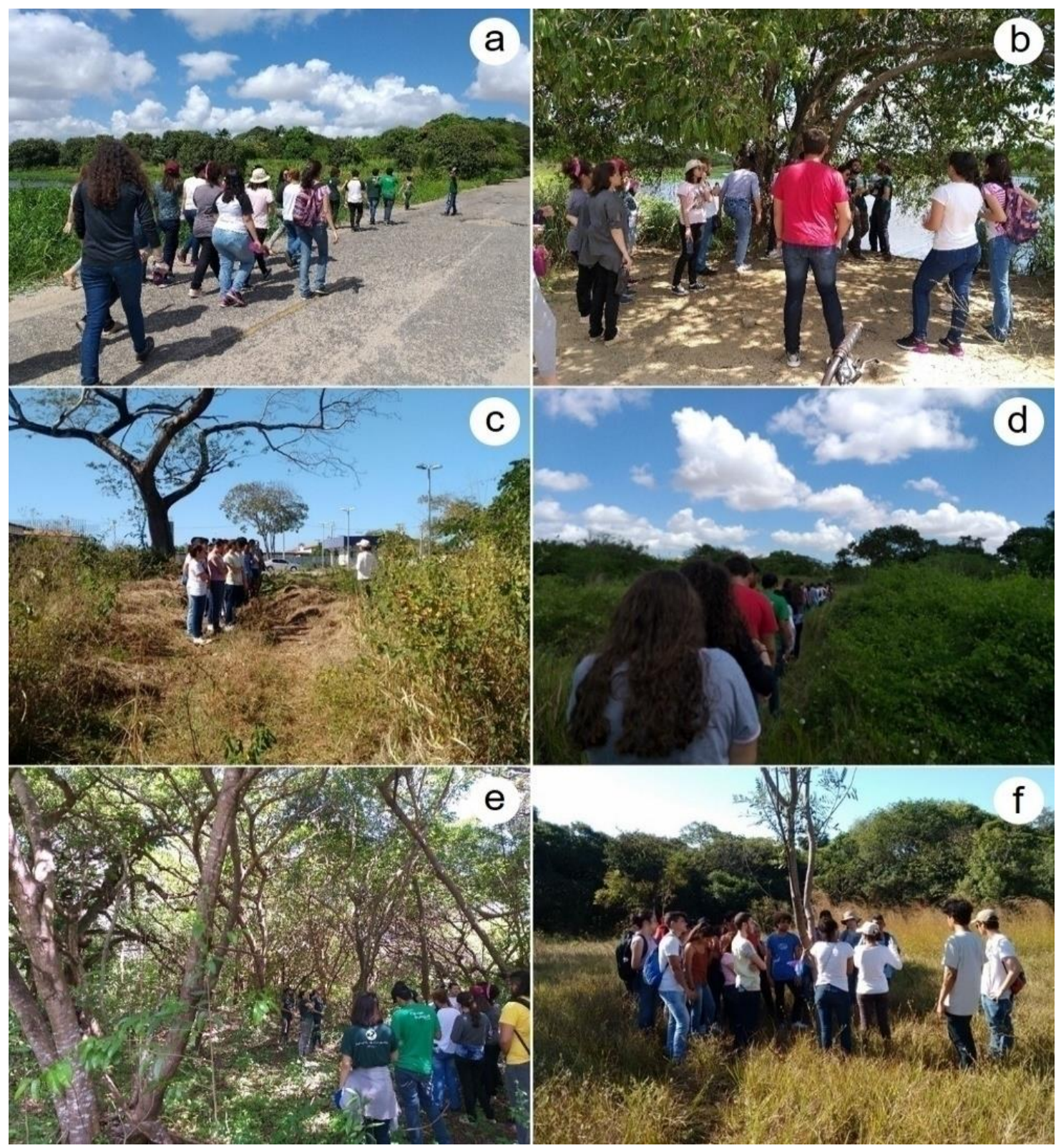

Figura 3: Trilhas realizadas com discentes do Curso de Licenciatura em Ciências Biológicas na área verde da Universidade Estadual do Ceará, campus Itaperi, no município de Fortaleza-CE. Fonte: Almeida-Filho (2017/2019).

\section{RESULTADOS E DISCUSSÃO}

\subsection{Perfil sociodemográfico}

Os dados indicam predominância do sexo feminino (58\%), com faixa etária variando entre 17 e 32 anos e maior frequência do público adulto jovem (19-21 anos) com 42\% (Tabela 1). Esses dados corroboram com o perfil do público encontrado atualmente nas universidades brasileiras, segundo dados do Censo da Educação Superior de 2017, realizado pelo Instituto Nacional de Estudos e Pesquisas Educacionais Anísio Teixeira - INEP, as mulheres ocupam as maiores proporções em ingressos, matrículas e concluintes de graduação [20]. 
Tabela 1: Perfil sociodemográfico dos participantes da pesquisa sobre Unidades de Conservação e o potencial de trilhas como prática de Educação Ambiental em uma Universidade Pública de FortalezaCE. Fonte: elaborado pelos autores.

\begin{tabular}{|c|c|c|}
\hline Dados Sociodemográficos $(\mathrm{n}=50)$ & $\mathbf{N}$ & $\%$ \\
\hline \multicolumn{3}{|l|}{ Sexo } \\
\hline Masculino & 20 & $40 \%$ \\
\hline Feminino & 29 & $58 \%$ \\
\hline Indiferente/outro & 1 & $2 \%$ \\
\hline \multicolumn{3}{|l|}{ Idade } \\
\hline Adolescentes (17-18 anos) & 11 & $22 \%$ \\
\hline Adulto jovem (19-21 anos) & 21 & $42 \%$ \\
\hline Adulto (22-25 anos) & 15 & $30 \%$ \\
\hline Adulto (26-29 anos) & 2 & $4 \%$ \\
\hline Adulto (30-34 anos) & 1 & $2 \%$ \\
\hline \multicolumn{3}{|l|}{ Situação conjugal } \\
\hline Solteiro & 49 & $98 \%$ \\
\hline Casado/União estável & 1 & $2 \%$ \\
\hline \multicolumn{3}{|l|}{ Com quem reside } \\
\hline Pai e/ou mãe e irmão(s) & 32 & $64 \%$ \\
\hline Mãe & 8 & $16 \%$ \\
\hline Pais & 6 & $12 \%$ \\
\hline Parente(s) & 1 & $2 \%$ \\
\hline Amigo(s) & 1 & $2 \%$ \\
\hline Esposa/marido e filho(s) & 1 & $2 \%$ \\
\hline Irmão(s) & 1 & $2 \%$ \\
\hline \multicolumn{3}{|l|}{ Tem filhos } \\
\hline Sim, 1 filho & 1 & $2 \%$ \\
\hline Não & 49 & $98 \%$ \\
\hline \multicolumn{3}{|l|}{ Exerce atividade remunerada } \\
\hline Sim, menos de 1 salário mínimo & 15 & $30 \%$ \\
\hline Sim, entre 1 e 2 salários mínimos & 8 & $16 \%$ \\
\hline Sim, não informou & 1 & $2 \%$ \\
\hline Não & 26 & $52 \%$ \\
\hline
\end{tabular}

Outros aspectos do perfil sociodemográfico dos participantes demonstram maior predominância de participantes solteiros (98\%), que residem com o pai e/ou mãe e irmão(s) (64\%), que não possuem filho (98\%) e não exercem atividade remunerada (52\%) (Tabela 1).

Em pesquisa realizada recentemente com $84,95 \%$ da totalidade de discentes do curso de Ciências Biológicas da UECE, campus Itaperi, verifica-se o mesmo cenário identificado na presente pesquisa, prevalecendo participantes do sexo feminino, com faixa etária de adultos jovens e solteiros [16]. Ainda, o fato de ser observado que em sua maioria são solteiros, residem com os pais e não possuem filhos, assim como, retratado no estudo supracitado, revela o caráter de dependência destes quanto ao suporte familiar.

\subsection{Conhecimento sobre Unidades de Conservação}

A princípio foi questionado aos participantes se sabiam o que é UC e obteve-se que $88 \%$ afirmaram que sim e $12 \%$ não. Ao analisar as respostas positivas e a nuvem de palavras (Figura 4), encontraram-se as seguintes categorias: Área de Proteção Ambiental (72,72\%), Conservação da Biodiversidade $(45,45 \%)$ e Uso Sustentável $(13,63 \%)$. 


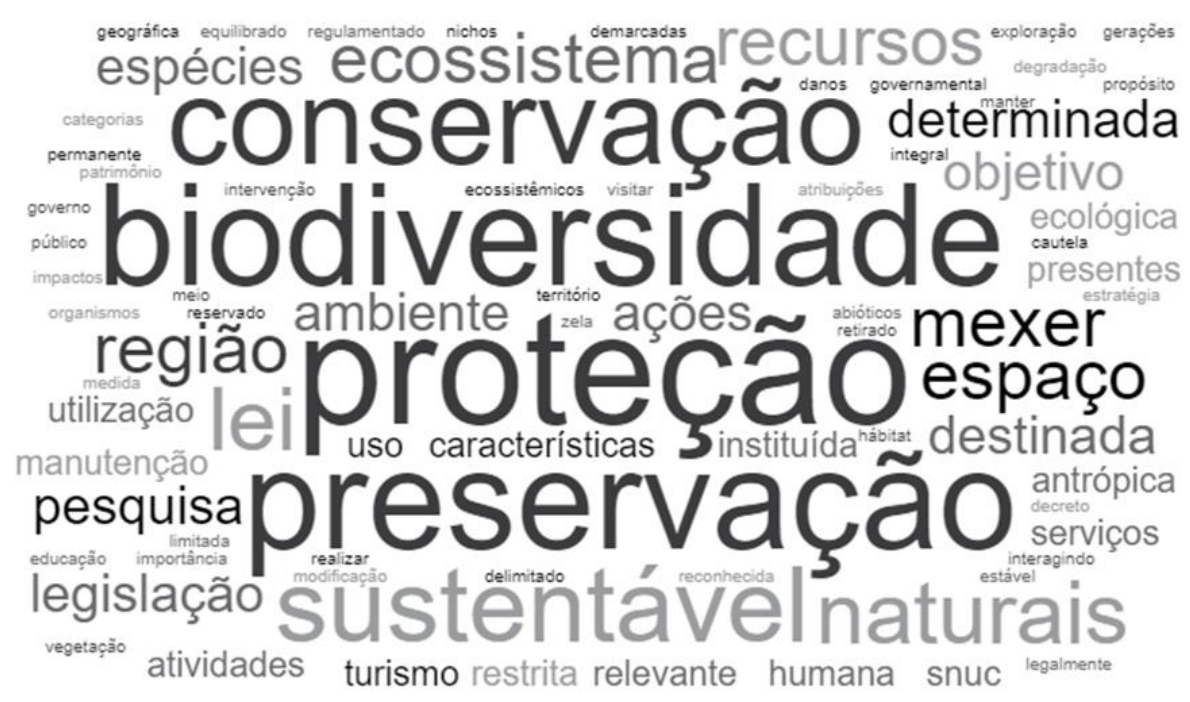

Figura 4: Nuvem de palavras criada acerca do conhecimento dos participantes da pesquisa sobre Unidades de Conservação e o potencial de trilhas como prática de Educação Ambiental em uma Universidade Pública de Fortaleza-CE. Fonte: elaborado pelos autores.

O conhecimento sobre o conceito de UC predomina entre os participantes, possivelmente por se tratar de um público universitário e deste conceito estar inserido no currículo do curso. Quanto às categorias encontradas com base nas respostas de fato caracterizam uma UC e seus objetivos e atribuições, desse modo, os mesmos souberam enfatizar os enfoques da "proteção", "conservação" e "uso sustentável dos recursos naturais" preconizados pelo SNUC.

Investigando esse questionamento com outros públicos, têm-se percentagens menores de conhecimento, como exemplo, em estudo realizado com 60 visitantes do Parque Natural Municipal Chico Mendes no Rio de Janeiro, que 50\% dos pesquisados tinham conhecimento sobre o que seria uma UC e destes, 70,3\% afirmaram que sua funcionalidade estava relacionada à conservação e/ou preservação da natureza [18].

Igualmente, Pradeiczuk, Renk e Danieli (2015) [21] obtiveram em seu estudo feito com 16 residentes do entorno da UC Parque Estadual das Araucárias, em Santa Catarina, que 10 moradores desconheciam o termo UC. Esse resultado se assemelha a outras pesquisas de percepção ambiental que destacam a dificuldade de moradores e visitantes de definirem o que seria uma UC, bem como o órgão gestor responsável pela área [22, 23].

Já para o Ensino Médio, o desconhecimento acaba se sobressaindo mais ainda, como constatado na pesquisa feita por Campos et al. (2016) [24] com 54 alunos de Ensino Médio de uma escola no estado do Piaú, na qual apenas 4 estudantes da totalidade souberam responder de forma correta o conceito de UC, 7 não souberam responder e 43 responderam incorretamente.

Analisando individualmente algumas respostas, desta pesquisa, como a do Participante 20, por exemplo, que definiu a UC como "área de preservação contra ações antrópicas", esse é um dos motivos de criação de uma UC, uma vez que atua como uma importante estratégia de redução das ações danosas do ser humano sobre o meio ambiente [25].

Para o Participante 18 uma UC é um "local instituído por decreto ou outra medida legislativa que define um espaço para proteção". As UC podem ser federais, estaduais ou municipais e em conformidade com o SNUC [1], essas podem ser criadas por intermédio do Poder Público da União, dos Estados ou dos Municípios, através de Lei ou Decreto e somente extintas, reduzidas ou recategorizadas por lei [26].

À vista disso, a criação de UC funciona como mecanismos ativos de conservação in situ da biodiversidade [27], assim como analisado na perspectiva dos Participantes 16 e 50, ao alegarem que UC são "regiões que precisam de conservação por terem espécies de plantas e animais interagindo com o ambiente" e "áreas demarcadas com finalidade de conservar a fauna, flora e recursos abióticos", respectivamente. 
Segundo o Ministério do Meio Ambiente [28] a cada ano sobe o número de espécies ameaçadas de extinção no Brasil, número esse que aumentou dez vezes quando se refere à flora desde o ano de 1968, ao mesmo tempo em que também cresceu a quantidade de espécies com deficiência de dados. Referente à fauna, o número de espécies ameaçadas passou de 45 em 1968 para 232. Nesse sentido, assim como, citado pelos participantes desta pesquisa, mostra-se a importância das UC com a finalidade de salvaguardar essa biodiversidade tão afetada e com ameaças crescentes [29].

No bioma exclusivamente brasileiro, a Caatinga, a criação de áreas protegidas significa a manutenção da fauna e flora e dos seus serviços ecossistêmicos, uma vez que se trata de uma região com recorrentes danos e desmatamentos e que refletem diretamente no processo de deterioração ambiental, na perda e ameaça à biodiversidade [30]. Essa situação é extremamente preocupante, pois é o bioma menos estudado e protegido do Brasil e o com menor prioridade de investimentos em conservação [31, 32].

Em relação à terceira categoria encontrada, de Uso Sustentável, nota-se a semelhança entre respostas, como as dos Participante 4, 12 e 23: que definem UC como sendo "uma área protegida legalmente da ação humana, tendo várias categorias em que o vão servir para pesquisa, turismo sustentável, entre outras", "uma área protegida por lei, porém que pode haver uso sustentável desta área" e "uma área de conservação aberta para visitar, que servem para turismo ecológico e também para realizar pesquisas", respectivamente. Como já mencionado, as UC atuam na proteção da fauna, flora e dos atrativos naturais e que em determinadas categorias é possível utilizar-se da exploração dos recursos naturais para fins científicos, educacionais, recreativos e/ou turísticos [33].

Diante das diferentes UC existentes, na categoria de Uso Sustentável é permitido o uso direto e controlado de recursos naturais. Esse atributo favorece também a proteção efetiva da biodiversidade e dos recursos naturais que passam a estar associados à produção e consumo sustentável e à agricultura e à população e residentes, que vivem e usufruem destas áreas [34].

Nessa lógica, o turismo ecológico ou ecoturismo proporciona um maior contato entre o homem e o meio natural, ao mesmo tempo em que promove a conscientização ambiental [35]. Esse segmento surgiu no intuito de contemplação da natureza, propiciando novas experiências e contribuindo para a conservação dos ecossistemas, do mesmo modo que incentivou e fortaleceu a economia e o envolvimento das comunidades locais [36].

Portanto, destaca-se que a prática do turismo confere maior destaque às potencialidades das UC, possibilitando atingir as finalidades para as quais estas foram criadas, principalmente em áreas de parques que desenvolvem atividades mais lúdicas, chamando maior atenção dos frequentadores quanto às questões ambientais [37].

Um dos objetivos das UC segundo o SNUC é de possibilitar meios e incentivos para a realização de estudos, pesquisa científica e monitoramento ambiental [1]. Assim, além da pesquisa em si e da divulgação dos seus resultados, um ponto relevante a se destacar é a integração desses dados ao manejo das UC [38], que proporciona uma gestão ambiental mais efetiva, servindo assim para planos de ação direcionados à conservação de determinadas espécies/grupos específicos [38].

Quando questionados se conheciam alguma UC no Ceará, 96\% dos participantes afirmaram que sim e apenas 4\% que não. Dentre as UC citadas, destaca-se o Parque Estadual do Cocó $(52,08 \%)$, Parque Nacional de Ubajara $(29,16 \%)$ e a APA e Parque da Sabiaguaba $(20,83 \%)$ (Figura 5). 


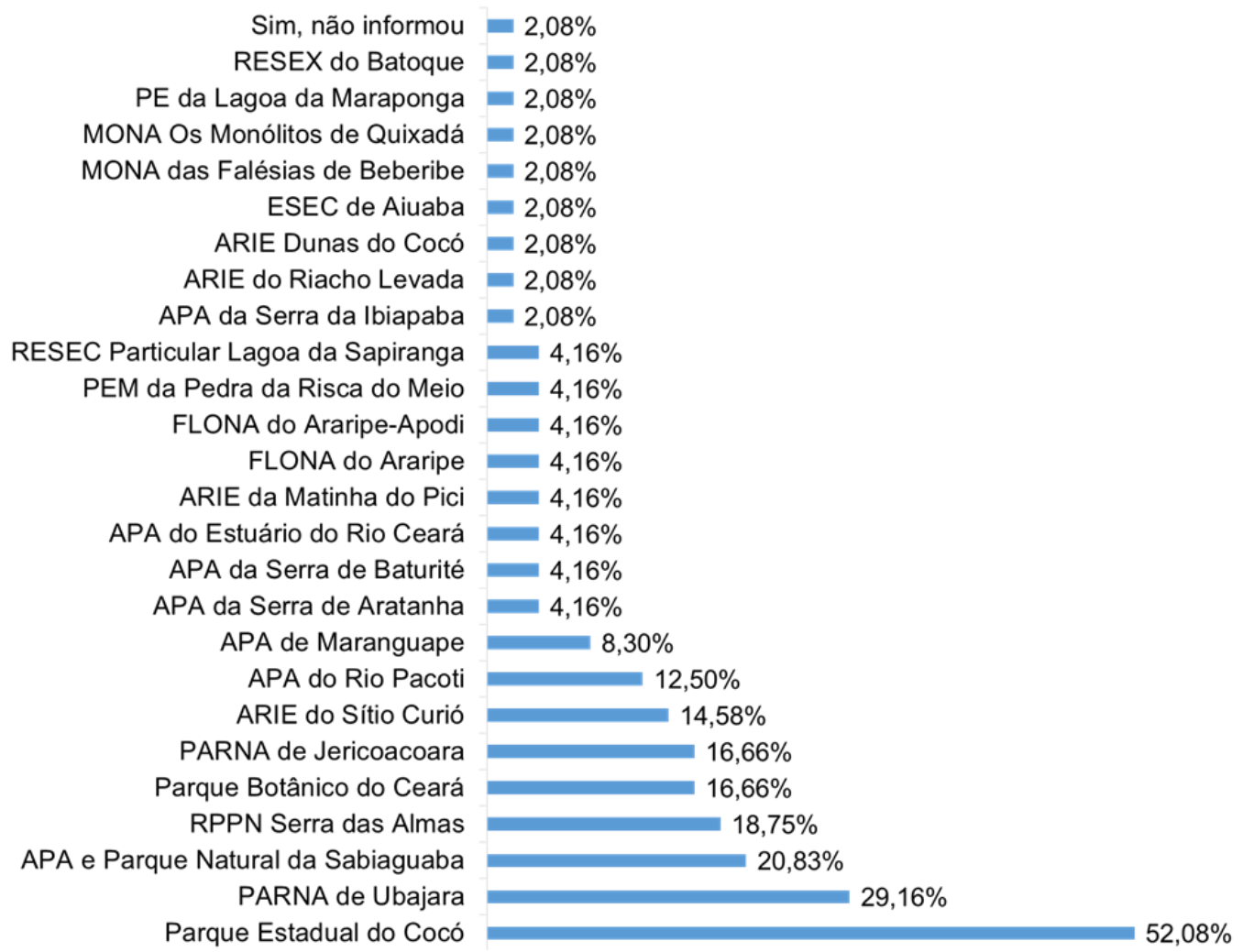

Figura 5: Unidades de Conservação do Ceará citadas pelos participantes da pesquisa sobre Unidades de Conservação e o potencial de trilhas como prática de Educação Ambiental em uma Universidade Pública de Fortaleza-CE $(n=48)$. Legenda: Nota explicativa: RESEX = Reserva Extrativista; PE= Parque Ecológico; MONA= Monumento Natural; ESEC= Estação Ecológica; $A R I E=$ Área de Relevante Interesse Ecológico; $A P A=$ Área de Preservação Ambiental; RESEC = Reserva Ecológica; $P E M=$ Parque Estadual Marinho; FLONA= Floresta Nacional; PARNA= Parque Nacional; RPPN= Reserva Particular do Patrimônio Natural. Fonte: elaborado pelos autores.

Em 2018 estima-se que os parques nacionais brasileiros receberam um total de 12 milhões de visitantes, atingindo novo recorde em relação ao ano anterior [39]. O Parque Estadual do Cocó destaca-se por ser um dos maiores parques urbanos com 1.571 hectares de área protegida e estar situado em uma área importante da capital Fortaleza [40]. Devido a sua dimensão e fácil localização, o Parque recebe muitos turistas e moradores locais que buscam, em meio ao ambiente urbano, usufruir das áreas verdes como forma de lazer, utilizando-se das trilhas, áreas abertas e equipamentos para uso recreativo, complexo esportivo e outros [41]. No local, é possível contemplar o ecossistema Manguezal, sendo esse responsável por cobrir boa parte do estuário do rio Cocó e que apresenta uma rica biodiversidade e é chamado de berçário natural das espécies [42].

O Parque Nacional de Ubajara é também uma importante área natural e atrativa, que recebe intenso fluxo de visitantes nacionais e internacionais, sendo o único parque no país possível de verificar a transição entre vegetações características de ambientes seco e úmido, além de possuir fauna e flora diferentes das típicas encontradas no semiárido. Reflexo esse da peculiaridade quanto aos fatores climáticos, marcados por elevados níveis pluviométricos devido à altitude da Chapada da Ibiapaba [43, 44].

A Área de Proteção Ambiental e Parque Natural Municipal das Dunas de Sabiaguaba, é uma área de maior facilidade de acesso e proximidade, uma vez que está inserida no extremo leste do litoral de Fortaleza, que apresenta uma extensa faixa de praia, lagoas costeiras e interdunares e campos de dunas móveis, semifixas e fixas. Devido a esses componentes naturais, abriga uma rica biodiversidade, além da eminente fragilidade do ecossistema encontrado, destacando-se como uma área de expressivo interesse socioambiental e científico [45]. 
Um fator que possivelmente justifica algumas UC serem mais citadas pode estar relacionado às aulas de campo e visitas que ocorrem em disciplinas durante a graduação dos participantes, ou mesmo por pesquisas científicas desenvolvidas na UECE. Alguns desses lugares são: Parque Nacional de Ubajara Reserva Particular do Patrimônio Natural Serra das Almas, Parque Botânico do Ceará, Área de Proteção Ambiental da Serra de Baturité, entre outros. Por outro lado, nota-se também, a partir disso, que é necessário um maior direcionamento à divulgação e reconhecimento dessas UC, tanto no ambiente acadêmico, quanto na sociedade de forma geral.

\subsection{Vivências e trilha da UECE como potencial}

Inicialmente, foi indagado se os sujeitos já haviam participado de alguma trilha e $62 \%$ afirmaram que sim e $38 \%$ que não. Geralmente dentro de áreas verdes como já mencionado, esse tipo de atividade atrai o público e é bastante conhecida e utilizada no contexto da EA, em que os interessados passam a ter a liberdade de vivenciar a realidade do ambiente e usufruir do meio natural [17].

Quanto ao questionamento se já conheciam a área verde da UECE antes da trilha, 72\% declararam que não e apenas $28 \%$ que sim. Na mesma lógica, questionou-se em que momento haviam tido esse contato com a área e dentre as respostas positivas, as principais foram através de pesquisa científica $(35,71 \%)$ e disciplinas do curso $(21,42 \%)$ (Figura 6).

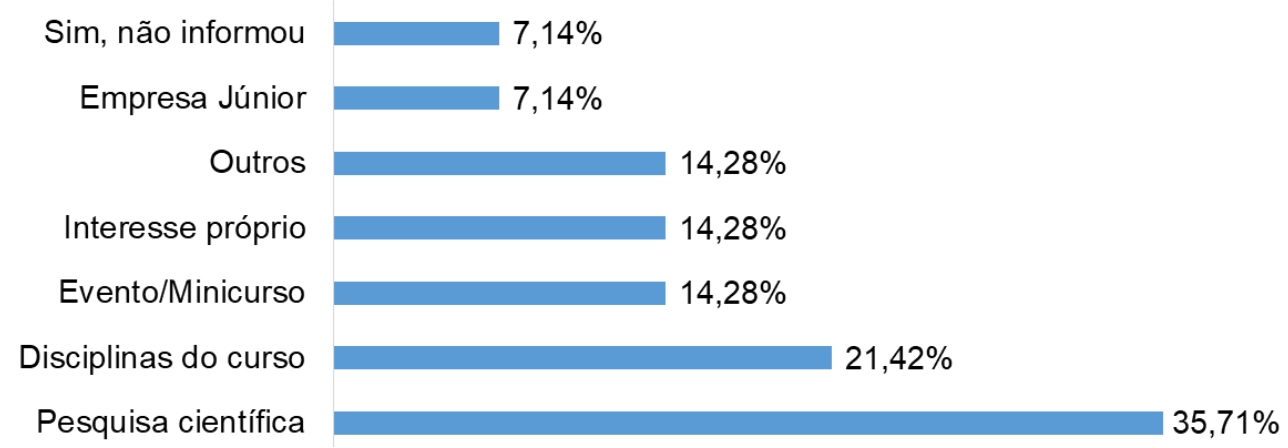

Figura 6: Experiências anteriores nas trilhas/mata da UECE dos participantes da pesquisa sobre Unidades de Conservação e o potencial de trilhas como prática de Educação Ambiental em uma Universidade Pública de Fortaleza-CE $(n=14)$. Fonte: elaborado pelos autores.

Vinculado ao Curso de Ciências Biológicas existem diferentes laboratórios que realizam ou já realizaram pesquisas envolvendo a fauna e flora residentes do campus, bem como, relacionadas à balneabilidade e qualidade dos corpos d'água existentes, o que justifica o momento mais citado no questionamento supramencionado. Acerca da fauna, vale destacar a presença de aves migratórias utilizando-se dos recursos do campus como refúgio dentro da área urbana, como é o caso da espécie Tyrannus savana [46].

Já em relação ao segundo momento citado, isso é atribuído principalmente à disciplina Morfologia e Anatomia de Espermatófitas, na qual os discentes precisam realizar coleta de material botânico para a confecção de um herbário e os estudantes encontram no campus uma rica diversidade de vegetação disponível para tal.

Foi inquirido aos participantes, se esses haviam gostado dos percursos realizados na área verde da UECE e a maior parte afirmou que sim (96\%). Em seguida, indagou-se se na sua concepção atualmente o campus possui potencial de atração de público para visitação de trilhas, $40 \%$ responderam que sim, pouco; $20 \%$ que não; $22 \%$ que sim, de forma intermediária; e $18 \%$ que sim, muito.

A UECE/campus Itaperi possui uma área física de preservação natural de 24,87 hectares de vegetação costeira e com habitats diferentes ao longo do campus, incluindo corpos d'água, campos abertos e áreas de mata fechada, proporcionando diferentes ambientes e cenários que 
podem ser visualizados durante percursos e trilhas. Esses ambientes podem possibilitar aos frequentadores um meio atrativo por apresentar elementos naturais, sendo relevante na promoção da conscientização e na preservação ambiental [47].

Nesse sentido, como atrativos para a visitação de trilhas na mata da UECE, os participantes destacam a interação com o meio ambiente (90\%), flora (86\%) e em seguida informações e conhecimento $(84 \%)$ (Figura 7). As trilhas de fato permitem aos frequentadores uma maior interação com o ambiente natural e vegetação e conforme Marinheiro et al. (2016, p. 59-60) [48]: "buscam transformar estes espaços naturais em locais de vivência que promovam o encantamento pela natureza, construindo valores, atitudes e mudanças culturais e sociais, em cooperação, para a preservação do bioma local".

Apesar da fauna não estar em maior relevância entre os atrativos citados pelos participantes, é possível destacar que no campus existe uma rica diversidade de animais, na qual já são registradas pelo menos 129 espécies de aves [49].

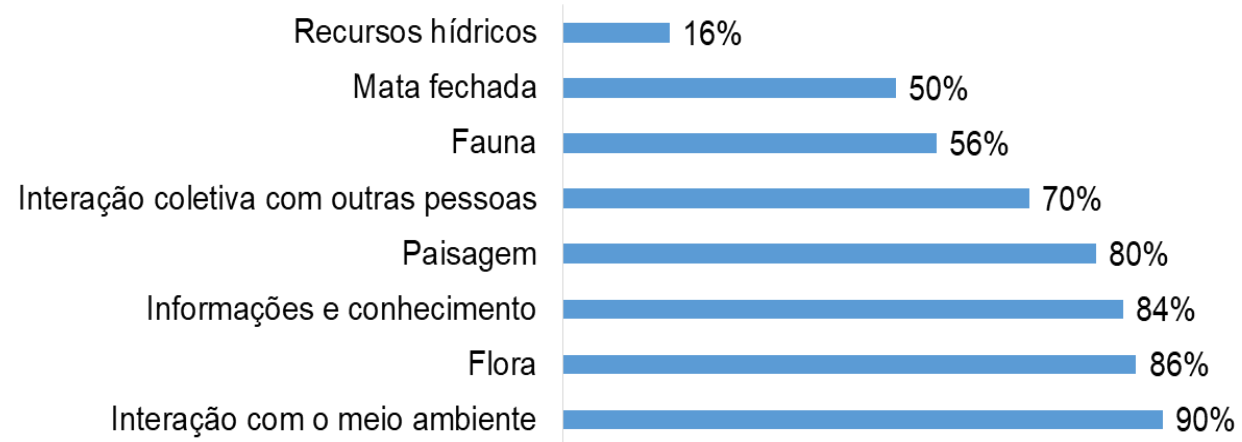

Figura 7: Atrativos da trilha/mata da UECE, segundo os participantes da pesquisa sobre Unidades de Conservação e o potencial de trilhas como prática de Educação Ambiental em uma Universidade Pública de Fortaleza-CE (n=50). Fonte: elaborado pelos autores.

Segundo Scremin (2015) [50], são diversos os atrativos e benefícios proporcionados pelas trilhas. como o conhecimento e orientações acerca do local e das relações ambientais e ecológicas existentes, que podem ser encontradas disponíveis nas placas informativas ou por intermédio de guias; apreciação da natureza e biodiversidade em seu meio natural; e também para a saúde física e mental, gerando bem-estar e reduzindo o estresse [51].

Foi perguntado qual a importância/contribuição de trilhas em uma UC e identificou-se com maiores relatos: contribui para a EA (96\%), contribui para a conservação/preservação ambiental (82\%) e estimula o turismo sustentável (82\%) (Figura 8). Atividades de EA nesse tipo de ambiente apresentam como principal objetivo a mudança de ações da população em relação ao ambiente, contribuindo para o desenvolvimento e formação de novas ideias e saberes que ajudam na conservação da biodiversidade e nas questões ambientais [52]. 


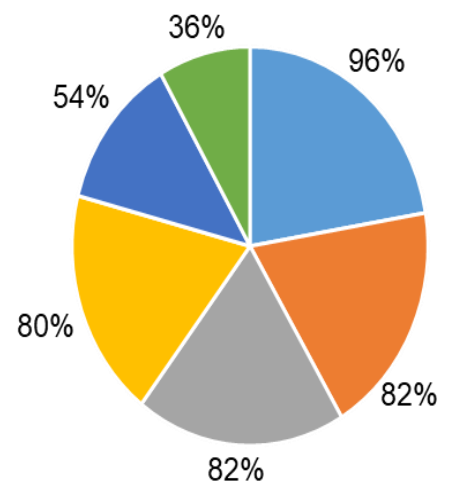

\author{
ロ Contribui para a Educação Ambiental \\ ఐ Contribui para a Conservação/Preservação Ambiental \\ —Estimula o Turismo Sustentável \\ —Conhecimento sobre a importância da existência da área \\ - Encoraja a participação da comunidade \\ — Geração de renda, trabalho e movimentação da economia
}

Figura 8: Importância/contribuição de trilhas em uma UC, segundo os participantes da pesquisa sobre Unidades de Conservação e o potencial de trilhas como prática de Educação Ambiental em uma Universidade Pública de Fortaleza-CE $(n=50)$. Fonte: elaborado pelos autores.

Percebe-se então, que a sensibilização em si já se destaca e atua como um importante contribuinte para a EA e preservação ambiental, uma vez que essa ferramenta pode contribuir no momento inicial de escolha e decisão da população quanto aos seus valores ambientais e tomadas de decisão. As atividades de EA em UC apresentam-se com caráter mais direto e participativo junto aos frequentadores do lugar. Dessa forma, favorece a transmissão do conhecimento, que se torna mais efetiva quanto aos valores e relações do meio ambiente, além de ajudar na conservação do local [53]. Ao mesmo tempo, assim como citado pelos participantes, contribuem para a conservação/preservação ambiental uma vez que este tipo de recurso beneficia a ideia de recuperação e preservação dos espaços degradados através da ação antrópica [54].

Assim como aborda a Lei $\mathrm{n}^{\mathrm{o}} 11.771$ de 17 de setembro de 2008, um dos objetivos do turismo é: "propiciar a prática de turismo sustentável nas áreas naturais, promovendo a atividade como veículo de educação e interpretação ambiental e incentivando a adoção de condutas e práticas de mínimo impacto compatíveis com a conservação do meio ambiente natural" [36]. As trilhas funcionam então, como procedimentos e opções sustentáveis marcantes para o segmento do ecoturismo, sendo de importância nas UC, logo gera retorno ao local através das visitas realizadas em cada área.

\title{
3.4 Trilha como atividade de Educação Ambiental
}

Foi indagado se os participantes achavam que a trilha realizada na UECE possui potencial como prática de EA e verificou-se concordância positiva em 100\% das respostas. Segundo Freitas (2017) [55], as trilhas ecológicas são excelentes ambientes para ser realizado trabalho de EA, logo, ajuda a permitir uma maior interação com a natureza.

Seguindo esse contexto, foi perguntado também qual temática os participantes acreditam que pode ser abordada em ações de EA nestas trilhas e, a partir disso, nota-se maior predominância da conscientização (98\%), impactos ambientais (98\%) e biodiversidade (96\%) (Figura 9). Segundo Souza (2014) [56], as trilhas são fundamentais no processo de sensibilização e conscientização ambiental, principalmente se tratando da EA não formal, visto que, possibilita o contato do indivíduo com o ambiente natural, levando o mesmo a despertar a percepção, observação e análise daquele meio com a finalidade do posterior interesse em preservar e conservar. 


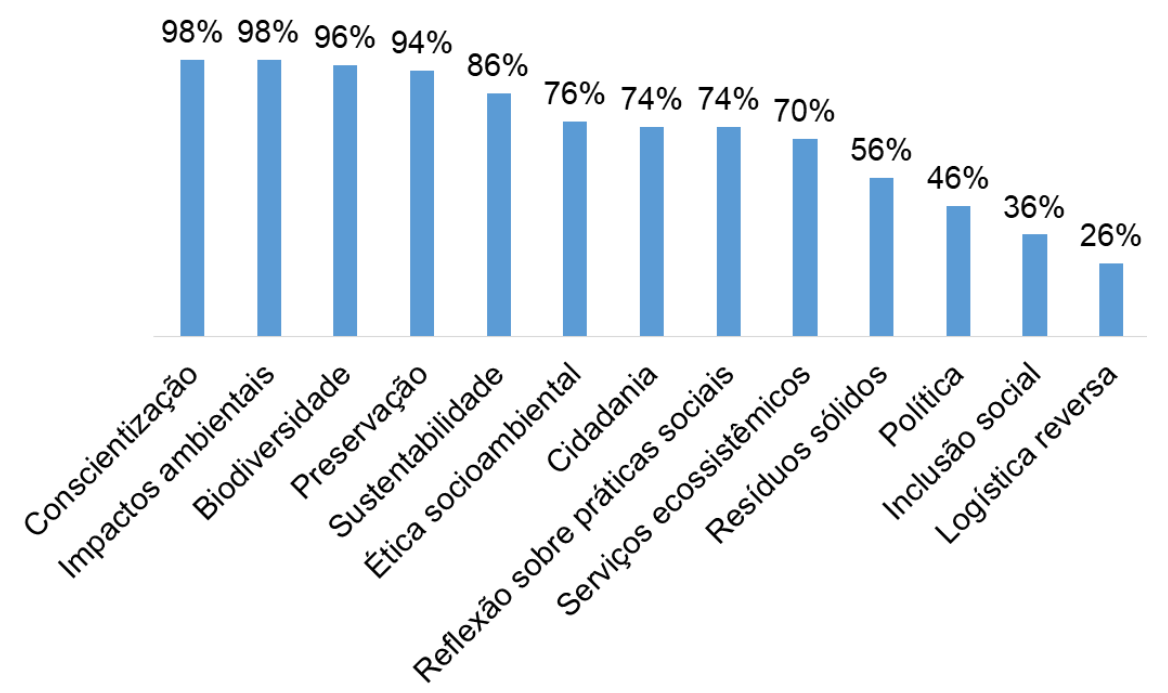

Figura 9: Temáticas que podem ser abordadas em ações de Educação Ambiental, segundo os participantes da pesquisa sobre Unidades de Conservação e o potencial de trilhas como prática de Educação Ambiental em uma Universidade Pública de Fortaleza-CE (n=50). Fonte: elaborado pelos autores.

Analisando no contexto das UC, a EA pode englobar diversas outras temáticas e abordagens, assim como, citado pelos participantes da presente pesquisa. Por intermédio da EA, os indivíduos e a sociedade são capazes de vivenciar e conhecer as áreas naturais sob proteção, resultando tanto em ações desenvoltas para a conservação desses espaços, bem como, na integração, fortalecimento e empoderamento por parte dos indivíduos que passam a desenvolver sentidos e vivências e conhecem a natureza, cultura e as populações do entorno [57].

Já sobre em que momento as trilhas podem ser utilizadas como atividade de EA na UECE, os participantes citaram em aulas práticas e/ou de campo (96\%), pesquisas científicas (96\%) e recepção de calouros (92\%) (Figura 10).

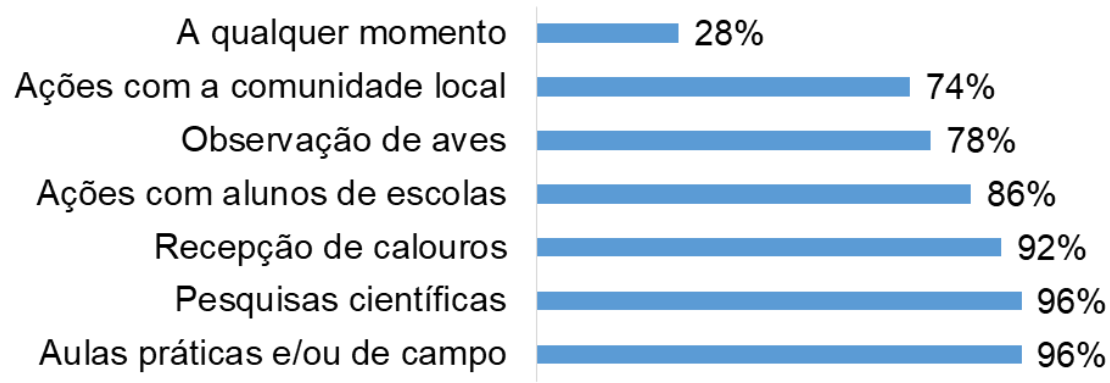

Figura 10: Momentos de realização de trilhas no ambiente acadêmico, segundo os participantes da pesquisa sobre Unidades de Conservação e o potencial de trilhas como prática de Educação Ambiental em uma Universidade Pública de Fortaleza-CE (n=50). Fonte: elaborado pelos autores.

De acordo com Copatti, Machado e Ross (2010) [58], a utilização de trilhas como recurso pedagógico para a EA deve desenvolver nos alunos o raciocínio lógico, a prática investigatória e a capacidade de observação e reflexão, ao mesmo tempo em que são trabalhados conceitos importantes de Ecologia. No âmbito escolar e acadêmico, faz-se importante o uso desse recurso como aula prática e/ou de campo, podendo gerar um melhor aproveitamento dos conteúdos em relação às aulas teóricas.

Em relação às pesquisas científicas citadas pelos participantes, essas já ocorrem há alguns anos e continuam até hoje, no intuito de identificar o potencial do local, podendo ser inseridas nesses momentos de EA. Em pesquisas mais atuais, quanto à biodiversidade, por exemplo, elaboradas 
pelo Grupo de Discussão em Herpetologia (GDH/UECE), já se tem conhecimento de uma rica diversidade, com pelo menos 13 espécies de anfíbios, 7 de lagartos, 10 de serpentes e 1 de Testudines catalogadas $[59,60]$.

Perante suas características atrativas e de paisagem, como já mencionadas anteriormente, a área verde do campus pode propiciar todos estes momentos apontados pelos participantes. Vale ressaltar que a Empresa Júnior de Biologia da UECE mediante conhecimento destes recursos, torna oportuno todo início de semestre letivo com os novos estudantes que ingressam no curso, a visitação a esse local e por meio de trilhas guiadas, apresenta a área verde sob diferentes ângulos e perspectivas e desperta o senso crítico quanto ao novo ambiente com o qual esses estudantes passarão a conviver. Passos e Prado (2013) [61] reforçam essas questões em seu trabalho, ao utilizarem trilhas como trote ambiental e mecanismo de EA, afirmando que esse tipo de situação pode proporcionar aos acadêmicos, comportamentos humanos e de interação com os novos ambientes da instituição.

A área verde da UECE/campus Itaperi encontra-se situada em uma localidade bastante urbanizada, cercada por várias residências e empreendimentos. Essa urbanização e proximidade com áreas urbanas causam impacto negativo no ambiente e apesar de não ser o foco do trabalho, esses pontos são discutidos durante os percursos guiados pela Empresa Júnior, também citados pelos participantes da pesquisa (Figura 9). Então, mais que conhecimento, esses ambientes envolvem momentos de sensibilização, valorização e socialização de aprendizados e que enriquecem a experiência coletiva como espaço educativo [62].

Os espaços cedidos pelo campus para infraestruturas que são precárias e necessárias no Bairro da Serrinha podem ser utilizados como meios de EA em ações com alunos de escolas e com a comunidade local, por meio de iniciativas que aproximem essa população ao meio natural. Uma alternativa que está sendo bastante disseminada e praticada atualmente, que move cada vez mais público e que também esteve presente nas respostas dos participantes, é a observação de aves. Para Mamede, Benites e Alho (2017, p. 159) [63], em seu estudo realizado no Pantanal:

\begin{abstract}
Pode-se dizer que as expedições para observação de aves têm se caracterizado também como uma tecnologia social que visa à sustentabilidade através do ecoturismo, o qual procura valorizar a sociobiodiversidade, fortalecendo os laços interpessoais, aprimorando o conhecimento do cidadão sobre a diversidade biológica do Pantanal e aproximando as pessoas aos diversos elementos da natureza, além de fomentar a valorização das Unidades de Conservação, espaços naturais muitas vezes desconhecidos do público.
\end{abstract}

Dessa maneira, é notória a significância da execução de trilhas em áreas verdes como prática de EA, uma vez que proporcionam e despertam valores que ultrapassam o bem-estar pessoal, e passam a ressignificar olhares e cuidados com o meio ambiente. Ao ponto que também ajudam na conscientização e preservação ambiental, principalmente se tratando de remanescentes de áreas verdes em ambientes urbanos, como é o caso da mata da UECE/campus Itaperi.

\title{
4. CONCLUSÃO
}

Fundamentado nos dados obtidos no referido estudo, percebe-se que em Unidades de Conservação e outras áreas verdes é possível, através da realização de trilhas, proporcionar a diferentes públicos conhecimentos e experiências diretas com o meio natural. Nesse segmento, a UECE/campus Itaperi possui extensão e atrativos suficientes que podem ser facilmente visualizados e que foram também apontados pelos participantes, para utilizar-se da Educação Ambiental como fator positivo para disseminar um maior conhecimento acerca da área, suas particularidades ecológicas e a sensibilização para conservar e proteger esse e outros ambientes.

Nessa perspectiva, sugere-se que esse tipo de atividade permaneça sendo executada e venha a abranger um maior e diferenciado público e que possa envolver também a comunidade do entorno, uma vez que através da Educação Ambiental, as pessoas envolvidas acabam atuando de forma positiva como multiplicadores de conhecimentos e experiências e conhecendo as áreas verdes. Ainda, propõe-se a criação de uma Unidade de Conservação regulamentada e que garanta a 
manutenção dessas áreas verdes do campus e da fauna, assim como, de todas as atividades desenvolvidas no local.

\section{REFERÊNCIAS BIBLIOGRÁFICAS}

1. Brasil. Lei $\mathrm{n}^{\circ}$ 9.985, de 18 de Julho de 2000. Regulamenta o art. 225, § 1o, incisos I, II, III e VII da Constituição Federal, institui o Sistema Nacional de Unidades de Conservação da Natureza e dá outras providências. Brasília (DF): Diário Oficial da República Federativa do Brasil; 2000.

2. Oliveira JP. Análise da participação e percepção da comunidade local sobre o uso turístico em Unidades de Conservação Estadual no RN [dissertação]. Natal (RN): Universidade Federal do Rio Grande do Norte; 2019. $141 \mathrm{p}$.

3. Maciel LA, Siles MFR, Bitencourt MD. Alterações na vegetação herbácea de floresta ombrófila densa decorrentes do uso em uma trilha turística na Serra do Mar em São Paulo, Brasil. Acta Bot Bras. 2011;25(3):628-632, doi:10.1590/S0102-33062011000300016

4. Venturieri B, Santana A. Concepções sobre meio ambiente de alunos do ensino fundamental em BelémPA: estudo de caso com a E. E. E. F. M. prof. Gomes Moreira Junior. Rev Bras Educ Amb. 2016;11(1):234-245.

5. Nelson SP. Uso Público nas Unidades de Conservação. In: Cases MO, organizador. Gestão de unidades de conservação: compartilhando uma experiência de capacitação. Brasília, WWF-Brasil; 2012. p. 215237.

6. Sales Júnior LG, Chaves DC, Bezerra MC. Inventário preliminar da ornitofauna do Campus do Itaperi da Universidade Estadual do Ceará (UECE), Fortaleza-CE. In: Anais da I Semana Universitária da UECE; 1996; Fortaleza, CE. [place unknown]: UECE; 1996.

7. Lucena MF, Beleza AJF, Monteiro N, Teixeira RSC, Vasconcelos RH, Maciel WC. Levantamento de Avifauna do Campus Itaperi da Universidade Estadual do Ceará. In: Fraga AR et al., editores. Anais do V Simpósio Cearense de Animais Selvagens; 13 a 16 de setembro de 2016; Fortaleza, CE. [place unknown]: [publisher unknown]; 2016. p. 31-33.

8. Pequeno MGC, Sauvé JPG, Almeida MCV. Educação Ambiental no Ensino Superior: Qual seu lugar nos processos de formação docente?. In: Anais do V Congresso Internacional da AFIRSE; 18 a 21 de outubro de 2009; João Pessoa, PB. [place unknown]: [publisher unknown]; 2009.

9. Brasil. Ministério do Meio Ambiente. Diretrizes e recomendações para planejamento e a gestão da visitação em Unidades de Conservação. Brasília: Diretoria de áreas protegidas/Secretaria da biodiversidade e florestas; 2005.

10. Oliveira SRD, Silva MS, Tabosa WS, França BA, Silva MSP. Análise Geoambiental da Trilha Ubaia Doce - Parque Estadual Dunas do Natal "Jornalista Luiz Maria de Alves". Rev Geol. 2016 jan./jun;29(1):39-54.

11. Gil AC. Métodos e Técnicas de Pesquisa Social. 6. ed. São Paulo: Atlas; 2008. 220 p.

12. Universidade Estadual do Ceará. Plano de Desenvolvimento Institucional 2017-2021. Fortaleza: UECE; 2017. $120 \mathrm{p}$.

13. Azevedo R, Menezes KG, Barbosa RA, Neto JDRM, Monteiro JON, Coutinho AG, Sales Júnior LG. Aranhas epígeas de um fragmento de mata em área urbana em Fortaleza, Ceará, Brasil. Pesq Ens Ciênc Exat Natur. 2017 dez.;1(2):104-114, doi:10.29215/pecen.v1i2.449

14. Brasil. Lei no 12.651, de 25 de maio de 2012. Dispõe sobre a proteção da vegetação nativa; altera as Leis no 6.938, de 31 de agosto de 1981, 9.393, de 19 de dezembro de 1996, e 11.428, de 22 de dezembro de 2006; revoga as Leis no 4.771, de 15 de setembro de 1965, e 7.754, de 14 de abril de 1989, e a Medida Provisória no 2.166-67, de 24 de agosto de 2001; e dá outras providências. Brasília (DF): Diário Oficial da República Federativa do Brasil; 2012.

15. Brasil. Conselho Nacional de Saúde. Resolução No 510, de 07 de abril de 2016. Trata das especialidades éticas das pesquisas nas ciências humanas e sociais e de outras que utilizam metodologias próprias dessas áreas. Brasília (DF): Conselho Nacional de Saúde; 2016.

16. Almeida-Filho MA. Estilo de Aprendizagem dos discentes de um curso de Licenciatura em Ciências Biológicas no município de Fortaleza-CE [trabalho de conclusão de curso]. Fortaleza (CE): Universidade Estadual do Ceará; 2018. 94 p.

17. Maciel ABC, Lima ZMC, Morais ACS. Utilização da Trilha Ecológica como instrumento de educação ambiental: Parque da Cidade Dom Nivaldo Monte, Natal/RN. Rev Gest Neg Esp. 2017 Dez.;3(2):1-22.

18. Costa JR, Medeiros TA, Avelino-Capistrano F, Santos DMC. Parque Natural Municipal Chico Mendes: percepção da população acerca de uma Unidade de Conservação de Proteção Integral na cidade do Rio de Janeiro. Ciênc Atu. 2018 Mar.;11(1):2-17. 
19. WordClouds. Free online Wordcloud generator [Internet]. 2019 [acesso em 25 Out 2019]. Disponível em: https://www.wordclouds.com/.

20. Brasil. Ministério da Educação. Censo da Educação Superior; 2017. Disponível em: http://portal.mec.gov.br/docman/setembro-2018-pdf/97041-apresentac-a-o-censo-superior-ultimo/file. [Acesso em 10 Out 2019].

21. Pradeiczuk A, Renk A, Danieli MA. Percepção Ambiental no entorno da Unidade de Conservação Parque estadual das Araucárias. Rev Grif. 2015;34(38/39):13-32, doi: 10.22295/grifos.v24i38/39.3272

22. Câmara ES, Andriolli C, Vieira L. Vozes do campo e áreas protegidas: a percepção ambiental de pequenos proprietários rurais sobre os recursos naturais. Est Soc Agricul. 2017 Set.;25(3):568-590, doi:10.36920/esa-v25n3-5

23. Brito, D. M. C. Conflitos em Unidades de Conservação. PRACS: Rev Hum Cur Ciênc Soc UNIFAP. 2008 Dez.;1(1):1-12.

24. Campos AA, Batista RDC, Santos CA, de Souza MFL. Educação e percepção ambiental na área do Parque Nacional Serra da Capivara - PI. Plan Amaz: Rev Inter Dir Amb Pol Púb. 2016;(8):107-120, doi:10.18468/planetaamazonia.2016n8.p107-120

25. Gastal ML. Os instrumentos para a conservação da biodiversidade. In: Bensusan N, organizador. Seria melhor mandar ladrilhar?: Biodiversidade - como, para que, por quê. 2. ed. Brasília: Editora da UnB; 2008. p: 29-41.

26. Brasil. Ministério Público Federal. Nota Técnica $4^{\mathrm{a}}$ CCR n. ${ }^{\text {o }} 8 / 2017 ; 2017$ Disponível em: http://www.mpf.mp.br/pgr/documentos/nota-tecnica-pl-que-propoe-extincao-de-unidades-deconservacao. [Acesso em 10 Out 2019].

27. Ganem RS. Conservação da biodiversidade: legislação e políticas públicas. Brasília: Edições Câmara; 2010. 437 p.

28. Brasil. Ministério do Meio Ambiente. Monitoramento do desmatamento nos biomas brasileiros por satélite: monitoramento do bioma caatinga 2008-2009. Brasília: Ministério de Meio Ambiente; 2011. $46 \mathrm{p}$.

29. Joppa LN, Pfaff A. Global protected area impacts. Proc Roy Soc B-Biol Sci. 2011;278:1633-1638, doi:10.1098/rspb.2010.1713

30. Drumond MA, Kill LHP, Lima PCF, Oliveira MC, Oliveira VR, Albuquerque SG, Nascimento CES, Cavalcanti J. Estratégias para o uso sustentável da biodiversidade da Caatinga. In: Silva JMC, Tabarelli M, Fonseca MT, Lins LV, organizadores. Biodiversidade da Caatinga: áreas e ações prioritárias para a conservação. Brasília: MMA, UFPE; 2003. p. 329-340.

31. Leal IR, Tabarelli M, Silva JMC. Ecologia e conservação da Caatinga. Recife: Ed. Universitária da UFPE; 2003. 828 p.

32. Santos JC, Leal IR, Almeida-Cortez JS, Fernandes FW, Tabarelli M. Caatinga: the scientific negligence experienced by a dry tropical forest. Trop Cons Sci. 2011 Set;4(3):276-286, doi:10.1177/194008291100400306

33. Souza MANA. Mudanças na percepção dos usuários do Parque Sucupira, após a implantação de infraestrutura de recreação e esportes [trabalho de conclusão de curso]. Brasília (DF): Faculdade UnB Planaltina; 2017. 45 p.

34. Manetta BR, Barroso B, Arrais T, Nunes T. Unidades de Conservação. Eng On-line. 2016;1(2):1-10.

35. Scalco RF, Souza DE. Área de Proteção Ambiental Estadual das Águas Vertentes: instrumentos de gestão e potencial turístico. Cad Virt Tur. 2018 dez.;18(3):22-43, doi:10.18472/cvt.18n3.2018.1278

36. Brasil. Ministério do Turismo. Ecoturismo: orientações básicas. 2. ed. Brasília: Ministério do Turismo; 2010. $64 \mathrm{p}$

37. Santana CSCM. Análise de fatores que influenciam o apoio dos visitantes ao desenvolvimento do turismo na Unidade de Conservação Parque das Dunas, Natal/RN [dissertação]. Natal (RN): Universidade Federal do Rio Grande do Norte; 2018. 98 p.

38. Gonçalves TS. Contribuições da pesquisa científica para a gestão e manejo do Parque Nacional da Serra do Cipó e Área de Proteção Ambiental Morro da Pedreira em Minas Gerais. Rev Cient Elet Eng Flor FAEF. 2018 Ago;31(2):44-52.

39. Brasil. Ministério do Meio Ambiente. Parque nacionais batem novo recorde de visitação. [2019; acesso em 20 Out 2019]. Disponível em: https://mma.gov.br/informma/item/15401-parques-nacionais-batemnovo-recorde-de-visita\%C3\%A7\%C3\%A3o.html.

40. O Estado. Fortaleza tem o maior parque urbano do mundo. 05 Jun 2017 [acesso em 10 Out 2019]. Disponível em: https://www.oestadoce.com.br/geral/fortaleza-tem-o-maior-parque-urbano-do-mundo.

41. Lindoso TA, Santos LM, Paula DP. A importância da determinação do perfil dos visitantes do Parque Estadual do Cocó (Fortaleza, CE) para o seu manejo sustentável. Ver Cas Geog Sob. 2019 Set;21(2):755-770, doi: 10.35701/rcgs.v21n2.557 
42. Ceará. Secretaria de Meio Ambiente. Cocó: um guia para desfrutar as belezas. Fortaleza: Secretaria do Meio Ambiente; 2016. 15 p.

43. Brasil. Instituto Brasileiro do Meio Ambiente e dos Recursos Naturais Renováveis. Portaria $\mathrm{n}^{\circ} 170$, de 24 de dezembro de 2002. Estabelece o plano de manejo do Parque Nacional de Ubajara/CE. Brasília (DF): Diário Oficial da União; 2002.

44. Aragão TB. Valoração Econômica Ambiental aplicada no Parque Nacional de Ubajara/CE [dissertação] Fortaleza (CE): Universidade Federal do Ceará; 2017. 187 p.

45. Fortaleza. Prefeitura Municipal de Fortaleza. Plano de Manejo das Unidades de Conservação Parque Natural Municipal das Dunas de Sabiaguaba (PNMDS) e Área de Proteção Ambiental (APA) de Sabiaguaba. Fortaleza: [publisher unknown]; 2010. 304 p.

46. Martins BA, Coutinho AG, Rodrigues GSR, Monteiro JON, Cruz LBC, Matos NF, Sales-Júnior LG. Avifauna do Campus Itaperi da Universidade Estadual do Ceará, Fortaleza, Ceará. Anais do XXI Congresso Brasileiro de Ornitologia, Rio de Janeiro, Rio de Janeiro, Brasil, 6 a 12 de dezembro de 2014, XXICBO.

47. Rocha F, Barbosa FP, Abessa DMS. Trilha ecológica como instrumento de Educação Ambiental: estudo de caso e proposta de adequação no Parque Estadual Xixová-Japuí (SP). Rev Bras Ecot. 2019 Out;3(3):478-497, doi: 10.34024/rbecotur.2010.v3.5897

48. Marinheiro RC, Oliveira ACFC, Oliveira FM, Emanuelle MF, Pessoa A, Sargento JJA. Trilhas interpretativas: um caminho para a cidadania e a educação ambiental. Rev Práx: Sab Ext. 2016 Jul;4(7):59-68.

49. Rodrigues GSR. Guia fotográfico das aves do Campus do Itaperi - Universidade Estadual do Ceará: uma ferramenta de Educação Ambiental [trabalho de conclusão de curso]. Fortaleza (CE): Universidade Estadual do Ceará; 2014. 52 p.

50. Scremin SF. Trilhas - Uma volta ao ambiente natural APA - Guaratuba [trabalho de conclusão de curso]. Curitiba (PR): Universidade Federal do Paraná; 2015. 88 p.

51. G1. Trilhas e caminhadas ecológicas proporcionam benefícios à saúde física e mental. 2018 Mar 23 [revisado em 2019; acesso em 10 Out. 2019]. Disponível em: https://g1.globo.com/sp/itapetiningaregiao/especial-publicitario/fullrepel/maxima-protecao-nao-custa-caro/noticia/trilhas-e-caminhadasecologicas-proporcionam-beneficios-a-saude-fisica-e-mental.ghtml.

52. Brasil. Instituto Chico Mendes de Conservação da Biodiversidade - ICMBio. Educação ambiental em unidades de conservação: Ações voltadas para Comunidades Escolares no contexto da Gestão Pública da Biodiversidade. Brasília: ICMBio; 2016. 66 p.

53. Risso LC, Pascoeto JT. A percepção ambiental como contribuição na educação ambiental em trilhas de áreas protegidas e criação de roteiro interpretativo. Rev Elet Mest Educ Amb. 2016 Set/Dez;33(3):249264, doi:10.14295/remea.v33i3.5953

54. Steil CA, Carvalho ICM, Pastori EO. Educação ambiental não Rincão Gaia: por trilhas da saúde e da religiosidade numa paisagem ecológica. Educ. 2010 Jan/Abr;33(1):54-64.

55. Freitas CSS. Trilhas ecológicas educativas em espaços não formais no Parque Municipal Natural do Curió, Paracambi, RJ [dissertação]. Seropédica (RJ): Universidade Federal Rural do Rio de Janeiro; 2017. 105 p.

56. Souza MCC. Educação Ambiental e as trilhas: contexto para a sensibilização ambiental. Rev Bras Educ Amb. 2014;9(2):239-253.

57. Fundação Florestal. Educação Ambiental - Conceito. 2019 [acesso em 10 Out 2019]. Disponível em: https://www.infraestruturameioambiente.sp.gov.br/fundacaoflorestal/educacao-ambiental/educacaoambiental-conceito/.

58. Copatti CE, Machado JVV, Ross B. O uso de trilhas ecológicas para alunos do Ensino Médio em Cruz Alta-RS como instrumento de apoio a prática teórica. Educ Amb Ação. 2010 Out;34(9).

59. Bezerra LL, Rodrigues VL, Costa FRF, Almeida-Filho MA, Cassiano-Lima D. Anfíbios de um fragmento urbano de Tabuleiro Pré-litorâneo em Fortaleza-CE. In: Anais do $9^{\circ}$ Congresso Brasileiro de Herpetologia; 22 a 26 de julho de 2019; Campinas, SP. [place unknown]: [publisher unknown]; 2019.

60. Costa FRF, Bezerra LL, Rodrigues VL, Almeida-Filho MA, Cassiano-Lima D. Levantamento de répteis de um fragmento de Tabuleiro Pré-litorâneo de Fortaleza-CE. In: Anais do $9^{\circ}$ Congresso Brasileiro de Herpetologia; 22 a 26 de julho de 2019; Campinas, SP. [place unknown]: [publisher unknown]; 2019.

61. Passos MG, Prado GP. Avaliação do trote ambiental como atividade de Educação Ambiental na Universidade do Oeste de Santa Caterina, UNOESC Chapecó, SC. In: Anais do VI Encontro Regional Sul de Ensino de Biologia; 22 a 24 de maio de 2013; Sano Ângelo, RS. [place unknown]: URI; 2013.

62. Molleri C, Spuldaro SC, Pereira YCC. Transpondo os Muros da Escola: a importância da Unidade de Conservação para a vivência de Educação Ambiental. Enc Bios. 2011;7(12):150-158.

63. Mamede S, Benites M, Alho CJR. Ciência cidadã e sua contribuição na proteção e conservação da biodiversidade na Reserva da Biosfera do Pantanal. Rev Bras Edu Amb. 2017;12(4)153-164. 